\title{
The Role of the Dorsal Premotor Cortex in Skilled Action Sequences
}

\author{
Oleg Solopchuk, Andrea Alamia, and $\oplus^{-A l e x a n d r e ~ Z e ́ n o n ~}$ \\ Institute of Neuroscience, Université catholique de Louvain, 1200 Brussels, Belgium \\ Review of Ohbayashi et al.
}

Although the neural correlates of elementary movements are now fairly well established (Ejaz et al., 2015), understanding the neural circuits involved in complex motor skills such as sequential movements remains a challenge. Electrophysiological and lesion studies in monkeys, along with virtual lesion studies and neuroimaging data in humans, have shown that both the primary motor cortex (Lu and Ashe, 2005; Matsuzaka et al., 2007) and the non-primary motor cortex (Tanji and Shima, 1994; Wiestler and Diedrichsen, 2013; Wymbs and Grafton, 2013) are involved in sequential actions. Similar to other complex skills, movement sequences arise from multifaceted neural processing (Hardwick et al., 2013) involving the storage of the sequence in memory, the preparation of the movement kinematics, and the on-line movement correction. Correlative approaches, based on neuroimaging or primate electrophysiology, have failed to provide a clear mapping of these functions onto the different nodes of the motor network (Hardwick et al., 2013), a gap that interferential studies have the potential to fill.

Received April 8, 2016; revised May 17, 2016; accepted May 17, 2016.

This research was supported by the Fondation Médicale Reine Elisabeth, Fonds de la Recherche Scientifique, and Innoviris. The authors thank Etienne Olivier for his comments and suggestions, and Ervin Nimets for the help in figure preparation.

Correspondence should be addressed to Oleg Solopchuk, Institute of Neuroscience, Université catholique de Louvain, 53, Avenue Mounier, COSY- B1.53.04S, 1200 Brussels, Belgium. E-mail: oleg.solopchuk@uclouvain.be.

DOI:10.1523/JNEUROSCI.1199-16.2016

Copyright $\odot 2016$ the authors $\quad 0270-6474 / 16 / 366599-03 \$ 15.00 / 0$
One such study was recently conducted by Ohbayashi et al. (2016), who investigated the role of dorsal premotor cortex (PMd) in the execution of internally generated and visually guided sequences. Two monkeys were trained to execute visually cued movements, which were either random or belonged to a set of extensively trained sequences. The authors observed that in well trained sequences the animals started to exhibit anticipatory responses, indicating that movements within these sequences were internally generated rather than visually guided. During task performance, neural activity was recorded in the arm area of PMd, which was identified by means of microstimulation mapping. About half of the recorded PMd neurons were equally likely to be tuned to visually guided or internally generated sequential movements, suggesting the involvement of this area in both conditions. However, cell specificity was not determined according to statistical significance but following a liberal attribution criterion, making it difficult to determine the importance of the reported tuning properties. Therefore, Ohbayashi et al. (2016) used the GABA agonist muscimol to disrupt PMd activity to examine whether this brain region plays a causal role in sequence encoding. Importantly, they found that PMd inactivation led to reductions in the number of anticipatory movements and to increases in spatial error only during the execution of highly practiced sequences, suggesting that this region is involved in the control of internally generated sequences, but not visually guided movements.
These results raise important questions about the functional role of PMd in motor task performance. Indeed, the finding that PMd inactivation did not impair visually guided sequence performance appears to be in stark contrast with previous accounts of PMd involvement in controlling basic movement kinematics (Caminiti et al., 1991; Davare et al., 2015) and visually guided movements (Johnson et al., 1996). However, we believe that this apparent discrepancy may be explained by the presence of constant visual feedback during the task used by Ohbayashi et al. (2016), which, by allowing on-line correction of movement kinematics, may have concealed subtle inaccuracies in the initial movement parameters (Archambault et al., 2015; Davare et al., 2015). Given that the task design used in this study allowed the authors to measure only the accuracy and timing of the movement end point, but not of the whole trajectory, these disruptions of the reaching movement parameters could have gone unnoticed (Fig. 1). Conversely, the lack of visual guidance due to movement anticipation during internally generated sequences made performance more sensitive to disruptions in movement kinematics (Davare et al., 2015). This alternative interpretation could thus potentially account for the specific effect of a PMd temporary lesion on internally generated sequence performance.

As discussed by Ohbayashi et al. (2016), their study provides a new perspective on the specific role of PMd in sequence encoding by questioning the 


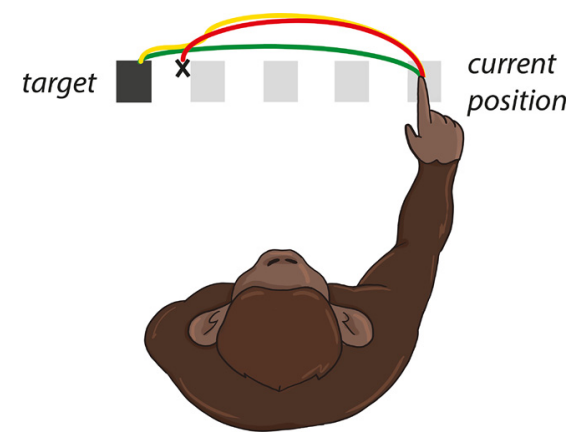

Figure 1. Simulated trial of the arm-reaching task used by Ohbayashi et al. (2016), in which monkeys were trained to execute internally generated and visually guided movements. The green line shows the optimal hand trajectory to reach the target. The authors reported that disrupting PMd did not result in error and concluded that visually guided movements do not depend on PMd integrity. An alternative explanation is that monkeys initiated a movement with a trajectory that would have resulted in missing the target (red line), but, because the target was constantly present, the monkeys were able to correct the trajectory late in the trial (yellow line).

importance of the supplementary motor area (SMA) to this function (Tanji and Shima, 1994). The authors propose to frame the functional roles of the two areas in terms of spatial and temporal sequence processing for PMd and SMA, respectively (Ohbayashi et al., 2016). This distinction was based on the observations that SMA is involved in the processing of temporally structured sequences (Tanji and Shima, 1994; Coull et al., 2016), and that the disruption of primate SMA did not induce impairments in the execution of spatially structured sequences (Nakamura et al., 1999). Addressing this issue directly requires comparing, under the same experimental conditions, the effect of the disruption of SMA and PMd on sequence performance. Following such an approach, Kennerley et al. (2004) used transcranial magnetic stimulation (TMS) to impair either pre-SMA or PMd while subjects were performing well trained finger movement sequences. TMS disruption of the pre-SMA had a marked effect on sequence performance, but only when the stimulation was delivered during the initiation of grouped movement series (i.e., chunks), suggesting the involvement of SMA in the retrieval of the sequence program. In contrast, PMd disruption did not produce any marked effect on sequence performance. In another study on motor sequence learning, Wymbs and Grafton (2013) used TMS over PMd and SMA to probe their roles in sequence retrieval, while varying the amount of training on the sequence-learning task. PMd disruption led to increased errors only during the retrieval of moderately trained sequences, as opposed to minimally or extensively trained sequences, whereas the inhibition of SMA increased errors regardless of the amount of training (Wymbs and Grafton, 2013). These results are in conflict with those reported by Ohbayashi et al. (2016), in which PMd inactivation affected selectively well trained movement sequences. However, task differences may also explain the discrepancy between these results, since Wymbs and Grafton (2013) used a finger sequence production task, whereas the design of Ohbayashi et al. (2016) involved armreaching movements, which may possibly engage PMd to a larger extent.

A possible confound in studying skilled motor functions, acknowledged by Ohbayashi et al. (2016), is that the performance of internally generated sequences is faster paced, and could consequently have been more susceptible to the disruption of the motor network than visually guided movements. To address this issue, they inactivated the shoulder representation in primary motor cortex (M1), which led to equivalent impairment of the visually guided and internally generated movement sequences. Interestingly, another influential study has investigated the role of $\mathrm{M} 1$ in sequence processing using a similar approach ( $\mathrm{Lu}$ and Ashe, 2005). Lu and Ashe (2005) found that M1 neurons show anticipatory activity to specific memorized movement sequences, and that muscimol injection in M1 disrupts long-trained sequences but leaves nonsequential motor performance unaltered ( $\mathrm{Lu}$ and Ashe, 2005). The study by Lu and Ashe (2005) as well as other studies (Matsuzaka et al., 2007) concluded from these findings that training duration is an essential factor in forming sequence representation in M1. Ohbayashi et al. (2016) did not report the duration of the training on the sequencelearning task, and probed only a specific part of $\mathrm{M} 1$, which again prevents a direct comparison between the studies. Therefore, the differential function of M1, PMd, and SMA in encoding movement sequences remains unsettled. Finally, Ohbayashi et al. (2016) suggest that other brain structures, such as the superior colliculus (SC), may be critical for visually guided movements. However, despite early descriptions of neural activity evoked by forelimb movement in SC (Werner, 1993) and the triggering of forelimb movements by SC electrical stimulation (Courjon et al., 2004), later findings have strongly contradicted the causal implication of SC in reaching (Stuphorn et al., 2000). For example, Stuphorn et al. (2000) re- ported that SC neurons were not modulated by any specific path of arm movement, or any muscle pattern (Stuphorn et al., 2000). Moreover, a recent study (Courjon et al., 2015) has shown that forelimb movements evoked by SC stimulation are systematically directed backward and downward, regardless of the site of the stimulation within the oculomotor map. These findings indicate that the SC is unlikely to be responsible for controlling visually guided movements, but, instead, is involved in the selection of the visual target (Krauzlis et al., 2013).

In conclusion, the contentious results reported by Ohbayashi et al. (2016) urge more in-depth investigation of the neural correlates of complex motor skills. We suggest that their findings remain compatible with an alternative interpretation in which PMd encodes movement kinematics, rather than being related prominently to encoding internally generated sequences. Nevertheless, it is our opinion that a systemic interferential approach, comparing the effect of the disruption of the different actors of the motor network on a unique task, would be beneficial to the field.

\section{References}

Archambault PS, Ferrari-Toniolo S, Caminiti R, Battaglia-Mayer A (2015) Visuallyguided correction of hand reaching movements: the neurophysiological bases in the cerebral cortex. Vision Res 110:244-256. CrossRef Medline

Caminiti R, Johnson PB, Galli C, Ferraina S, Burnod Y (1991) Making arm movements within different parts of space: the premotor and motor cortical representation of a coordinate system for reaching to visual targets. J Neurosci 11:1182-1197. Medline

Coull JT, Vidal F, Burle B (2016) When to act, or not to act: that's the SMA's question. Curr Opin Behav Sci 8:14-21. CrossRef

Courjon JH, Olivier E, Pélisson D (2004) Direct evidence for the contribution of the superior colliculus in the control of visually guided reaching movements in the cat. J Physiol 556: 675-681. CrossRef Medline

Courjon JH, Zénon A, Clément G, Urquizar C, Olivier E, Pélisson D (2015) Electrical stimulation of the superior colliculus induces nontopographically organized perturbation of reaching movements in cats. Front Syst Neurosci 9:109. CrossRef Medline

Davare M, Zénon A, Desmurget M, Olivier E (2015) Dissociable contribution of the parietal and frontal cortex to coding movement direction and amplitude. Front Hum Neurosci 9:241. CrossRef Medline

Ejaz N, Hamada M, Diedrichsen J (2015) Hand use predicts the structure of representations in sensorimotor cortex. Nat Neurosci 18:10341040. CrossRef Medline

Hardwick RM, Rottschy C, Miall RC, Eickhoff SB (2013) A quantitative meta-analysis and review of motor learning in the human brain. Neuroimage 67:283-297. CrossRef Medline 
Johnson PB, Ferraina S, Bianchi L, Caminiti R (1996) Cortical networks for visual reaching: physiological and anatomical organization of frontal and parietal lobe arm regions. Cereb Cortex 6:102-119. CrossRef Medline

Kennerley SW, Sakai K, Rushworth MF (2004) Organization of action sequences and the role of the pre-SMA. J Neurophysiol 91:978-993. CrossRef Medline

Krauzlis RJ, Lovejoy LP, Zénon A (2013) Superior colliculus and visual spatial attention. Annu Rev Neurosci 36:165-182. CrossRef Medline

Lu X, Ashe J (2005) Anticipatory activity in primary motor cortex codes memorized movement sequences. Neuron 45:967-973. CrossRef Medline

Matsuzaka Y, Picard N, Strick PL (2007) Skill representation in the primary motor cortex after long-term practice. J Neurophysiol 97: 1819-1832. CrossRef Medline

Nakamura K, Sakai K, Hikosaka O (1999) Effects of local inactivation of monkey medial frontal cortex in learning of sequential procedures. J Neurophysiol 82:1063-1068. Medline

Ohbayashi M, Picard N, Strick PL (2016) Inactivation of the dorsal premotor area disrupts internally generated, but not visually guided, sequential movements. J Neurosci 36:19711976. CrossRef Medline

Stuphorn V, Bauswein E, Hoffmann KP (2000) Neurons in the primate superior colliculus coding for arm movements in gaze-related coordinates. J Neurophysiol 83:1283-1299. Medline

Tanji J, Shima K (1994) Role for supplementary motor area cells in planning several movements ahead. Nature 371:413-416. CrossRef Medline

Werner W (1993) Neurons in the primate superior colliculus are active before and during arm movements to visual targets. Eur J Neurosci 5:335-340. CrossRef Medline

Wiestler T, Diedrichsen J (2013) Skill learning strengthens cortical representations of motor sequences. Elife 2:e00801. CrossRef Medline

Wymbs NF, Grafton ST (2013) Contributions from the left PMd and the SMA during sequence retrieval as determined by depth of training. Exp Brain Res 224:49-58. CrossRef Medline 